\title{
Quality open access publishing and registration to Directory of Open Access Journals
}

\author{
Xin $\mathrm{Bi}^{*}$ \\ Xi'an Jiaotong- Liverpool University, Suzhou, China
}

\begin{abstract}
With the fast development of open access publishing worldwide, Directory of Open Access Journals (DOAJ) as a community-curated online directory that indexes and provides access to high quality, open access, peer-reviewed journals, has been recognized for its high criteria in facilitating high quality open access scholarly publishing and used as the portal for accessing quality open access journals. While the numbers of journal application to be inclusion in DOAJ in Asia are kept increasing dramatically, many editors of these journals are not very clear about the idea or concept of the open access which have been embedded in the application form containing 58 questions falling into several different criteria categories. The very commonly seen misunderstanding of the required item, inaccurate or vague or incomplete and even missing information, poorly organized website, non-transparent process of publishing, especially no open access statement and copyright statement, or conflicts between the policy statements would cause much more communication between the reviewer and the editor and delay the completion of the review. This article gives an in depth introduction to DOAJ criteria and detailed introduction to the general process on how to register to DOAJ, suggestions based on application review also is given for journal editors to better prepare for this application. And it is the most important for editors to keep in mind that to be indexed by DOAJ is not just about filling a form, it is about truly change and adapt to best practices in open access publishing.
\end{abstract}

Keywords

Received: December 25, 2016 Accepted: February 8, 2017

Basic requirements; Best publishing practice; Directory of Open Access Journals criteria; DOAJ Seal; Open access publishing

Correspondence to Xin Bi

xin.bi@xjtlu.edu.cn

*Editor, China Ambassador, DOAJ

\section{Introduction}

ORCID

$\mathrm{Xin} \mathrm{Bi}$

http://orcid.org/0000-0002-9746-6506

The open access scholarly publishing is booming in recent years. Research shows that open access movement is now disruptive and is traversing the scientific, technical and medical pub- 
lishing industry with the speed and force of a tsunami [1]. This is also could be proved by the numbers of journals indexed by The Directory of Open Access Journals (DOAJ) which is the world recognized portal for quality open access journals. DOAJ was launched in 2003 at Lund University in Sweden with 300 open access journals indexed in the very beginning, the number of journals included in DOAJ has already increased dramatically and it contains more than 9,417 open access journals covering all areas of science, technology, medicine, social science and humanities.

The aim of DOAJ is to increase the visibility and ease of use of open access scientific and scholarly journals, thereby promoting their increased usage and impact. Also DOAJ aims to be comprehensive and cover all open access scientific and scholarly journals that use a quality control system to guarantee the content and thus to be the one-stop shop for users of open access journals [2]. Science Europe requires scientists to publish in DOAJ, Scopus, or Web of Science listed journals for European Union funded research [3]. On July 29, 2015, Scopus launched an open access indicator for journals indexed in Scopus. This indicator will allow users to easily identify open access journals within Scopus and journals are registered as being open access journals only if they are registered as gold open access or Subsidized open access at one or both of the following sources: DOAJ and the ROAD (Directory of Open Access Scholarly Resources) [4]. Here gold open access refers to those journals in which all peer reviewed scholarly articles are online available without any restrictions and for which an article processing charge (APC) has been paid while Subsidized open access do not charge an APC and are instead subsidized by other means, for example, by university, government, agency, corporate, sponsorship etc.

As DOAJ is very strict on and promoting the transparency and best practices of scholarly publishing [5], registration to DOAJ would not be just a procedure of filling the application form. The form itself is on the website of DOAJ at https:// doaj.org/application/new [6]. Especially for those publisher who is new to DOAJ criteria, before starting to fill into the form, the publisher shall be clear and prepared to meet the requirements of DOAJ.

As the current higher criteria for indexing into DOAJ has been launched in March 2014, some publishers are required to do the reapplication which started from January 2015, in this reapplication project all journals indexed before March 2014 need to reapply to be indexed in DOAJ [7].

The application form now is both used for new application and reapplication. Only Journals which meet the criteria of DOAJ would be regarded as qualified open access journals and be indexed into DOAJ. Although the application form itself is very self-explanatory with guides in different languages, necessary explanation to key question items, and guidance and tutorial provided on the DOAJ website, journal editors might still feel there is some difficulties for them to complete the form. Inaccurate information, missing information or malfunctioned webpage links provided in the application form also caused extra time for reviewers to complete an application. For each of the successful application into DOAJ, generally there would be quite many emails communication between the reviewer of DOAJ and the journal editor to help improve their publishing practice.

This article will go through the application question by question to deeply explain the DOAJ criteria based on the application form, to clarify the quality open access publishing principals and suggestion will also be given to help journal editor better deal with different situation which may occur.

\section{Evaluation Criteria and the Application Form}

DOAJ is worldwide recognized for its high standard criteria of inclusion journals. In June 2015, the Committee on Publication Ethics, the DOAJ, the Open Access Scholarly Publishers Association and the World Association of Medical Editors updated their joint statement, originally published in 2013: the principles of transparency and best practice in scholarly publishing [5]. These principles were to a considerable extent derived from the criteria for the admission of journals into DOAJ that were expanded, updated and put into practice in March 2014 [3]. DOAJ also updated its criteria as a response to the maturing open access arena, the greater demands made on open access publishing by questionable journals and publishers, and to retain DOAJ's relevancy and importance in open access publishing in 2014.

The new DOAJ criteria, as presented in the application form, are divided into 5 sections: (1) basic journal information with 35 questions (2) quality and transparency of the editorial process, from question 36 to question 43, (3) openness of the journal in question 44, (4) content licensing from question 45 to question 51, and (5) copyright and permissions from question to 52 to question 54 [3]. And the form is followed by 3 extra questions asking about the name and email address information of the person who filled the form.

Among all the 54 questions to be answered in the application form in the 5 sections mentioned above, they are generally falling into three categories, the general questions to collect information, basic requirements for entry into DOAJ and the recommendations of best practices of which if qualified a DOAJ Seal will be awarded.

For general questions, accurate information is required, if not applicable, it could be left blank as the answer, but the number of this general questions are very few in the applica- 
tion form. The basic requirements questions have to be answered with accurate information and also have to meet the criteria, all the basic requirements need to be met at the same time. In this article, all the basic requirement questions will be marked up. The third category is the best practice of which if a journal don't have the setting or such practice, it is still acceptable.

\section{General Questions and Basic Requirements}

Failed to meet any basic requirement will lead to failure to be included in DOAJ. These "must have" requirements generally includes an open access statement which comply with the Budapest Open Access Initiative (BOAI) definition, a peer-review process, an editor/editorial board with clearly identifiable members, licensing and copyright information, aims and scope of the journal, and the number of articles published per year shall be at least 5 per year.

\section{Basic journal information}

The journal title filled in for question 1 shall be exactly the same to what is shown on the journal website. Uniform resource locator (URL) of your journal's website for question 2 shall be accessible and it is the link to the dedicated website of the journal other than to a collection of journals or any other services. Whether the URL is a dedicated domain or a subdomain does not matter, but the journal must have an online space dedicated for it only. The Title and URL of journal are among the basic requirements for entry into DOAJ. Question 3 is asking for an alternative title, this would be a good place to fill in the journal title in your local language other than in English or a translation of the journal title. Question 4 is for print version of journal International Standard Serial Number (ISSN) and question 5 is for online version ISSN, there must

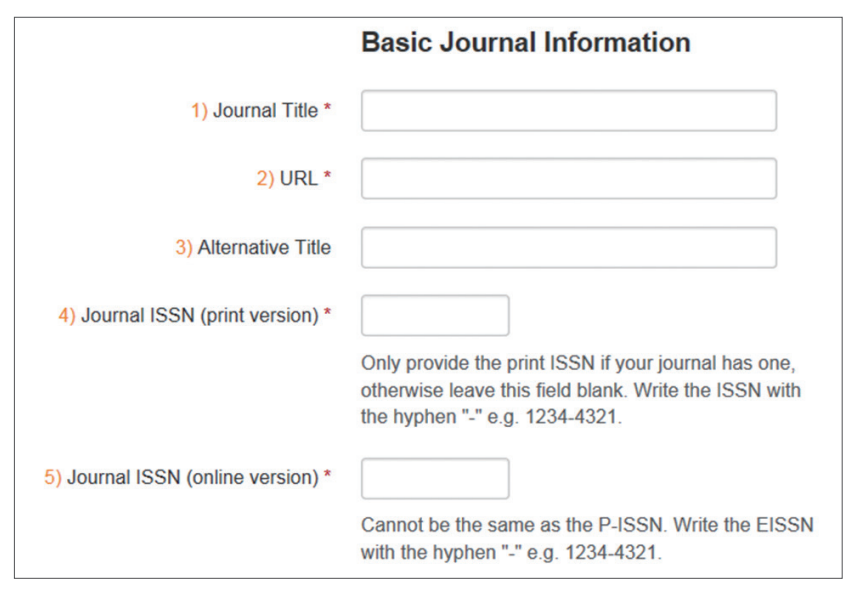

Fig. 1. Part sample of Directory of Open Access Journals application form. be a validate ISSN for a journal. The ISSNs shall be clearly shown in the webpage of the journal. If a journal has both print ISSN and eISSN, that is preferable, but if a journal has only one of them, it is acceptable as well. This is the basic requirements for entry into DOAJ. The ISSN information will be verified automatically by DOAJ via issn.org. Application from a journal with an unrecognized or not confirmed ISSN will be immediately rejected (Fig. 1).

Question 6 is for the name of the publisher, this should be responded with clear and accurate information. This is the basic requirements to entry into DOAJ. Question 7 is asking if there is any society or institution who is running the journal, if there was not, then leave it blank. Question 8 is about platform, host or aggregator, and also the form shows three samples for it as OJS, HighWire Press, and EBSCO, leave this item blank if it is not applicable to your journal, for example, your journal is hosted by your own website.

From question 9 to question 11 are the information about the contacts, this is very important as all the communication will go to the email provided here as contacts email address. Make sure the name of the contact is from a real person and that person is always reachable by emails. These 3 questions are basic requirements. Question 12 is asking in which country is the publisher of the journal based in. In case the journal is a joint venture between an institute in one country and an international publisher based in another country and the publisher is running the journal, then the name of the country of the publisher shall be filled in question 12. For example, this happens a lot in China as there are more and more collaborative newly created open access journals in international publisher's platform and be released in their packages as well, then the country of the publisher other than China shall be filled in for question 12. This question is one of the basic requirements.

Question 13 to question 20 are about article processing charges and submission fees. Some journals charge for APCs or submission fee and some not. In either case, the statement about charging shall be clearly stated on the journal website as URL shall be filled in the form containing information on this. If you answer "Yes" to question 13 and 17, then more questions will pop out asking you to fill in specific number of these APC and submission charge. These are basic requirements for entry into DOAJ.

Sometimes the editor indicated "No" to these questions in the application form and there is actually no such declaration on their website as they think if they don't mention any charges on website then this should be interpreted as "No charge" by people, but it is very important to make a clear statement even though there is not any charges to the authors during the publication process. For example it could be stated as "This 

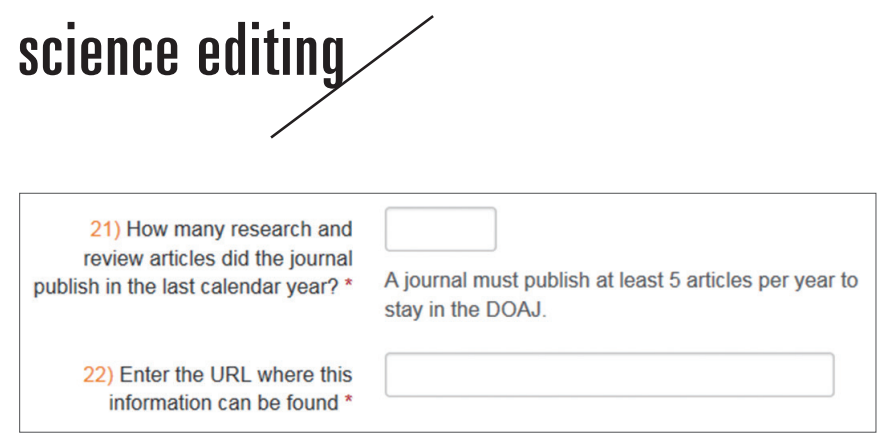

Fig. 2. Information of articles published.

journal does not charge APCs or submission charges". This is essential to the transparency of the publishing system.

There are also cases that the editors filled article processing charge per article in the application form but in practice they announced their charged based on each page on the website, in this case, the editor shall calculated an average charge per article and fill in that number in the application form. If a journal has different APCs per article then the highest charge must be entered into the application. Also attention shall be paid to choose the correct currency.

Question 21 and 22 refer to the number of articles published in the last calendar year, the minimum requirement for inclusion in DOAJ is to have at least 5 articles per year, and these articles shall be of the research article and review articles. For question 22 the URL could be the webpage of the archive. This is the basic requirement for entry into DOAJ (Fig. 2).

And question 23 is asking if there is a waiver policy for fees for developing country authors and if you answer "Yes" to question 23 then question 24 will pop up asking for a URL containing the waiving policy information. If you answered "No" to question 14 and 17 indicating the journal does not charge APC or submission fee, then choose "No" for question 23.

Question 25 and 26 are about digital archiving policy and they are not among the minimum requirements, these two questions will be explained in DOAJ Seal section in this article. In Korea, KoreaMed Synapse (https://synapse.koreamed. org/) and ScienceCentral (http://www.e-sciencecentral.org/) would be applicable as a digital archiving policy for question 25. Question 27 is very plain, if a journal allows software to automatically crawl the journal content, then choose "Yes", otherwise "No".

Question 28 and 29 are not among the basic requirements for being accepted in DOAJ, these two questions will be explained in the DOAJ Seal section in this article. Question 30 and 31 are about the article download statistics, if a journal don't have this setting, then choose "No", if "Yes", then the URL where this information can be found shall be provided in question 31.

Question 32 is asking the first calendar year in which a complete volume of the journal provided online open access content to the full text of all articles. This is applicable to the established journals who changed to online version. For new journals just fill in the year of establishment of the journal. This is the basic requirement for entry into DOAJ.

Question 33 is about the formats of the full text, fill in this item according to a journal's practice, tick all that apply. Generally PDF and HTML are two often used formats. This is the basic requirement for entry into DOAJ.

Question 34 is the item to state the keywords which best describe the scope of your journal. Please not to use the words like "international journal" or "good academic journal" as the keywords. All the keywords shall be input in lower case letters except they are names of people and places, and the maximum number of keywords are 6 and must be in English. This is the basic requirement for entry into DOAJ.

Question 35, input the languages that apply to your journal, multiple language allowed. The language here refers to the language used for your articles, not of those for the abstract and for your website.

\section{Quality and transparency of the editorial process}

DOAJ values the quality publishing and emphasize and the quality and transparency of the editorial process. The journal must have an editorial board, at least 5 of its members must be easily identified (with their affiliation information) and have a good reputation. In the case of Arts and Humanities, it is acceptable that there is no editorial board, but there shall be at least two editors doing the editorial review. An URL for the Editorial Board page shall be filled in question 36. This is a basic requirement for entry into DOAJ.

Question 37 and question 38 is about specification of the review process and for this question there is a drop down list containing the following options: editorial review, peer review, blind peer review, double blind peer review, open peer review and none. If there is no peer review process for a journal, it will failed to be included in DOAJ.

For this question, the common seen problem is that the option chosen in the application form doesn't match to the statement of peer review process in the journal website. For example, in question 37 "Double blind peer review" was picked but after in all the instructions on the website there is no such a "double blind" statement, in this case, for example, if the publisher mentioned peer review, then it have to be changed from "Double blind peer review" to "Peer review" to make sure information are consistent. "Editorial review" is normally only valid for Humanities journals. This is a basic requirement for entry into DOAJ.

Statements about aims and scope should be clearly visible on the website. Question 39 is asking for the URL for the journal's aims and scopes. This is a basic requirement for entry into DOAJ. Instructions to authors shall be available and easily located on the website, this is the Question 40 in the applica- 


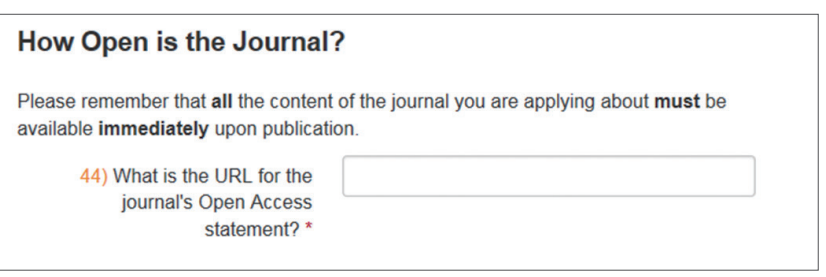

Fig. 3. Openness of the journal.

tion form. This is a basic requirement for entry into DOAJ.

Journals must state what measures they use to check for plagiarism before publication and this must be stated at the URL provided to question 41 in the application form, if "Yes" has been ticked then question 42 will pop out asking the URL where the information of screening for plagiarism can be found.

Time from submission to publication will concern authors. Question 43 is asking the average number of weeks between submission and publication. It should be noted that it is the number of weeks not the number of months.

\section{How open is the journal?}

In this section, there is one statement "Please remember that all the content of the journal you are applying about must be available immediately upon publication. Any journal with an embargo period will not be accepted in DOAJ, also DOAJ does not include hybrid journals. This is one of the basic requirements for entry into DOAJ (Fig. 3).

Question 44 is asking for the URL for the journal's open access statement. DOAJ is requiring there must be an open access statement in the website of the journal, which shall adhere to the BOAI definition which is quoted as below [8].

By "open access" to [peer-reviewed research literature], we mean its free availability on the public internet, permitting any users to read, download, copy, distribute, print, search, or link to the full texts of these articles, crawl them for indexing, pass them as data to software, or use them for any other lawful purpose, without financial, legal, or technical barriers other than those inseparable from gaining access to the internet itself. The only constraint on reproduction and distribution, and the only role for copyright in this domain, should be to give authors control over the integrity of their work and the right to be properly acknowledged and cited.

Here is an example of an open access statement, fitting the DOAJ criteria, that could be published on the publisher's website [9]:

This is an open access journal which means that all content is freely available without charge to the user or his/her institution.
Users are allowed to read, download, copy, distribute, print, search, or link to the full texts of the articles, or use them for any other lawful purpose, without asking prior permission from the publisher or the author. This is in accordance with the BOAI definition of open access.

\section{Content licensing}

From question 45 to question 51 are the questions related to the content licensing, and this might be the most difficult part for publishers. There are many cases in the application that there is no content licensing information at all, this might due to the different understanding of "open access" as publisher think the freely online available articles are "already" open access.

Quite often that a journal would be qualified on other DOAJ criteria but there is no licensing statement, then emails communication would be in place to suggest the publisher to adopt on license policies and it was very positive that most of the publisher will take action to make a license statement. Starting from question 45, it is asking "Does the journal embed or display simple machine-readable CC licensing information in its articles?". This is not one of the basic requirement for entry into DOAJ, it is one of the criteria for DOAJ Seal (refer to the DOAJ Seal section in this article).

DOAJ requires that in all instances the journal web site must state clearly and precisely the terms of use and reuse that readers and authors have when they submit an article or use the published content, particularly if the journal is not using a Creative Commons license (CC license, for more information, please refer to https://creativecommons.org/licenses/). This is a way of showing that the journal is sharing the published material to support a greater global exchange of knowledge. It is also a way of protecting the journal material from illegal use, for example, if the journal is stating that they prohibit reproduction or commercial use of your articles [9]. Thus it is notable that in question 47, there is no such an option as "None" among the list. All the available choices are CC BY, CC BY-CN, CC BY-NC-ND, CC BY-NC-SA, CC BY-ND, CC BY-SA and "Other" followed by an input box (Fig. 4).

If a journal is using a $\mathrm{CC}$ license and chose any option from one of the CC licenses, then you need to enter the URL on your site where your license terms are stated, for question 49 . If a journal publisher does not employ a CC license, then you have to choose "Other" as an option and then fill in your application form specifying what other usage terms apply, and then question 48 will pop up asking "Which of the following does the content require?" with options listed as attribution, no commercial usage, no derivatives, and share alike. These keywords are helping to describe your license statement. Here "Other" might be a contract, publishing agreement, publisher- 


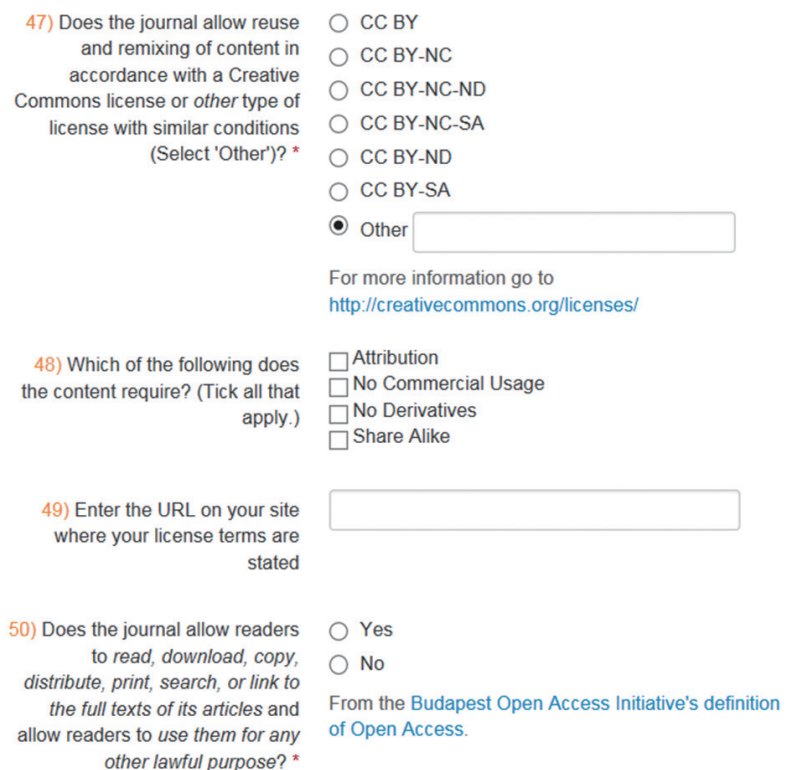

Fig. 4. Licensing the content.

specific license and these terms must be equivalent to the terms of the CC licenses that are listed in order to be accepted into DOAJ. When writing the journal's own license, DOAJ strongly advise publishers to get legal advice before adopting a standard text or constructing their own. You must make sure that you use the correct legal language. The information provided here does not constitute legal advice [9].

In both the two cases, either the journal have a CC license in place, or use their own licensing statement, DOAJ editors or reviewer of the application will visit your website and read the statement of your license to check if your choice of CC license in the application form is identical to what has been stated in the website. Changes might be made to your choices in order to make sure the consistence of the information. This is one of the basic requirements for entry into DOAJ.

The application of a CC license is encouraged but is not actually required for acceptance, it is currently one of the best practices and a journal using some of CC license would be applicable for a DOAJ Seal (refer to the "Reuse and remix of content" section in "DOAJ Seal" in this article).

Question 50 is asking "Does the journal allow readers to read, download, copy, distribute, print, search, or link to the full texts of its articles and allow readers to use them for any other lawful purpose?", this should also be align with the journal open access statement. If "No" has been chosen as an answer to this question, that means that this journal is not an open access journal and obviously will be rejected by DOAJ, as DOAJ is including open access journals only. This is one of the basic requirements for entry into DOAJ. Question 51 is

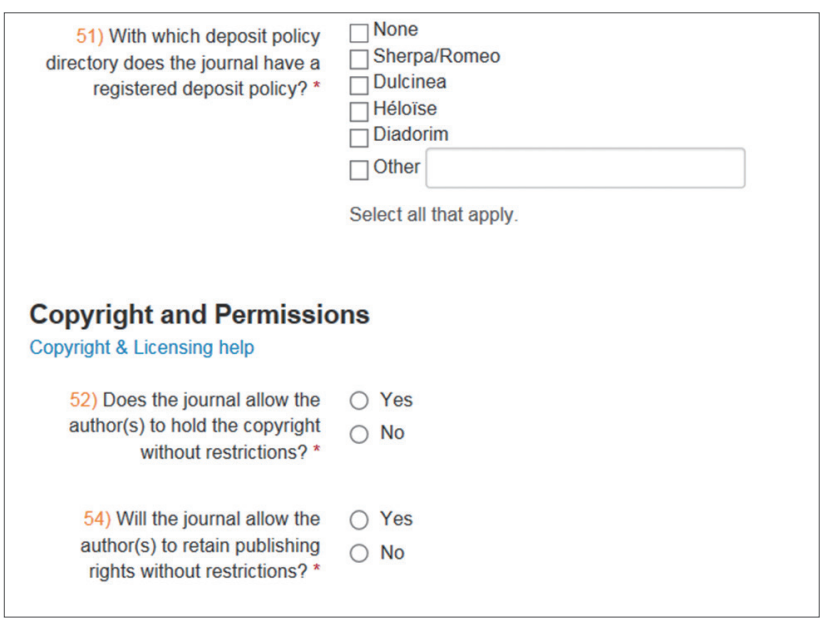

Fig. 5. Copyright and permissions.

one of the best practices which DOAJ is encouraging, refer to the DOAJ Seal section in this article for more information (Fig. 5).

\section{Copyright and permissions}

There is only two questions in this section, but they are very crucial and important questions and must be answered. Question 52 is one of the best practices for DOAJ Seal. Question 54 is asking "Will the journal allow the author(s) to retain publishing rights without restrictions?", the answer to this question do not have to be "Yes", but if "Yes", this answer shall be identical with the license statement of the journal which shall be found in the webpage provided in question 49. If the licensing statement actually means restricted publishing rights for authors, the answer to question 54 will be changed to "No".

\section{Best Publishing Practice and DOAJ Seal}

DOAJ promotes best practice in open access publishing. To highlight journals that adhere to best practices, DOAJ Seal for open access journals has been created. It shall be noted that a publisher shall not apply for DOAJ Seal as this is awarded based on the information provided in the application [6]. All these 7 items are not "must have" requirements for a journal to be accepted in DOAJ (Fig. 6).

\section{Long term digital archiving policy}

To make sure the journal content will not disappear in case of unstable internet access or problems with the availability of the journal website, it is a best practice to have an archival arrangement in place with an external party so that the content will not disappear when the service of publisher stopped. This requirement is reflected as question 25 "What digital ar- 


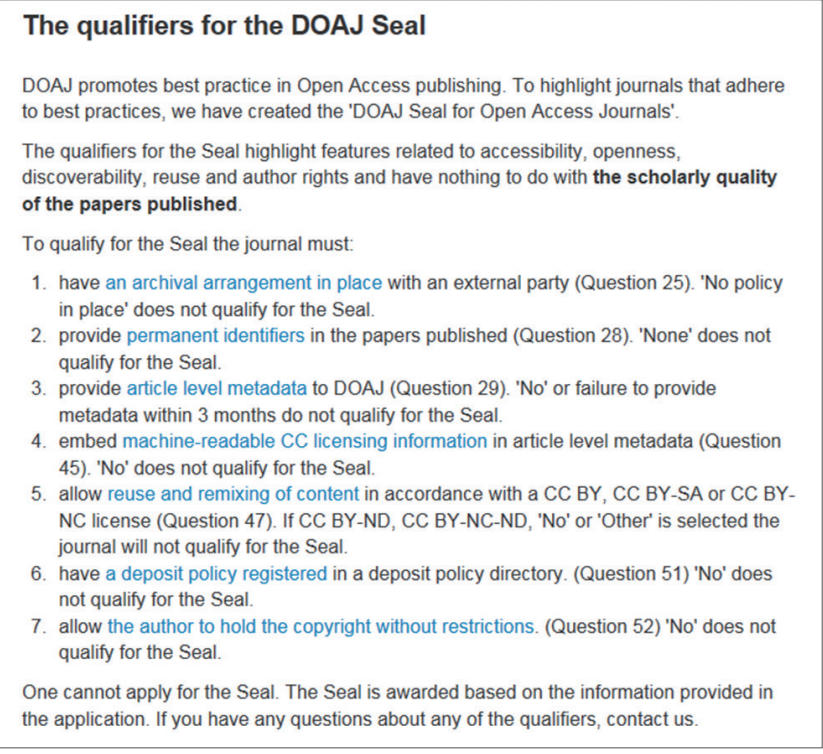

Fig. 6. The qualifiers for the DOAJ Seal.

chiving policy does the journal use?" in the application form. If "No policy in place" was chosen as an answer, it does not qualify for the Seal, but it is acceptable for inclusion in DOAJ. Other choices for this question includes digital preservation systems such as LOCKSS [10], CLOCKSS [11], PORTICO [12], PubMed Central (PMC)/Europe PMC/PMC Canada [13], these are all international collaborative efforts in archiving literature. Also a national library could be accepted as a digital depositing policy as the national library would generally be strong enough to exist for the long term, but a university repository would not be acceptable as a university level project may not be sustainable.

\section{Article identifiers}

The question 28 in the application form states as "Which article identifiers does the journal use?". If the journal publisher provide permanent identifiers in the papers published, this would meet one of the criteria for DOAJ seal. If the answer to this question is "None" then it does not qualify for the Seal. Among the choices, "DOI" stands for digital object identifier, the DOI system provides a technical and social infrastructure for the registration and use of persistent interoperable identifiers, called DOIs, for use on digital networks [14]. Also "Handles" is another infrastructure component in managing digital objectives [15]. "ARK" is the abbreviation for archival resource key and ARKs are URLs designed to support longterm access to information objects [16].

\section{Article level metadata}

The journal publisher provide article level metadata to DOAJ, this is the question 29 "Does the journal provide, or intend to provide, article level metadata to DOAJ?" in the application form. "No" or failure to provide metadata within 3 months do not qualify for the Seal.

\section{Machine readable CC license}

It is a best practice that the journal embed machine-readable CC licensing information in article level metadata, as today most people are downloading and reading in the article level, so the CC license in the article will make it more easy and clear to the users on the copyright issues. This is reflected as question 45 stating "Does the journal embed or display simple machine-readable CC licensing information in its articles?" in the application form. "No" does not qualify for the Seal. If "Yes" has been chosen then question 46 will show up asking for URL of an example page, this could generally be the URL of a specific journal article.

\section{Reuse and remix of content}

Question 47 states as "Does the journal allow reuse and remixing of content in accordance with a CC license or other type of license with similar conditions". If the publisher has one of the CC licenses or a similar conditions as their copyright statements, this would qualified as one of the minimum requirements. It is the best practice that the publisher allow reuse and remixing of content in accordance with a CC BY, CC BY-SA or CC BY-NC license, this will allow unrestricted copyright and publishing rights for people to use it. While the more limited conditions such as CC BY-ND, CC BY-NC-ND, "No" or "Other" is selected the journal will not qualify for the Seal.

\section{Deposit policy directory}

Question 51 is asking "With which deposit policy directory does the journal have a registered deposit policy?". The publisher have a deposit policy registered in a deposit policy directory. SHERPA/RoMEO is a service run by SHERPA to show the copyright and open access self-archiving policies of academic journals [17] and it accepts publishers from all over the world. Duclinea is only for Spanish scholarly journals [18]. Héloïse is only for "francophone" publishers [19]. Diadorim is only for Brazilian scientific journals [20]. "No" does not qualify for the Seal.

\section{Unrestricted copyright for authors}

The publisher allow the author to hold the copyright without restrictions and this is the question 52 "Does the journal allow the author(s) to hold the copyright without restrictions?" in the application form. "No" does not qualify for the Seal. If there is a copyright statement which is responding to question 47 , then the unrestricted copyright for authors should be 


\section{science editing /}

clearly stated. It is quite often seen that the editors chose "Yes" to question 52 but in their copyright statement, they say the publisher owns the exclusive copyright and in this case the answer to question 52 shall be changed to "No" or the publisher shall change their copyright statement.

\section{Frequently Asked Questions During the Application Process}

There are some key issues frequently appear during the process of an application and these issues are crucial to be good publishing practices and would be beneficial to the authors and users of the journal.

The first one is the website. All the necessary journal business information pages, including the journal's aims and scope, the editorial board, the instructions for authors, the description of the quality control system, the open access statement, the plagiarism policy, and the licensing terms, must be hosted on this same site and not be held centrally on another web site, or must be prominently linked to from the journal's homepage. This is a basic requirement for entry into DOAJ. Sometimes a journal is distributed in different sites and it could be seen that URLs filled in the application form are from different domain names, this should be definitely avoided. Everything should be in one dedicated, integrated and well organized dedicated website for the journal. Even for those publishers who own multiple journals, this principal shall be implemented to each of their journals. Archive materials shall also be integrated in the dedicated website of the journal as well.

It is important to identify any possible contradictions between your open access policy and your copyright policy, or any incompatibilities between your copyright policy and CC licensing. Sometimes there is an open access statement but the copyright license still indicating "all rights reserved by the publisher", or CC BY license has been stated but there is this wording like "by accepted for publication, the author transfer exclusive rights to the publisher" in the license statement.

Publishers may choose to use a non-CC license but then need to make sure their content license shall be similar or equivalent to a CC license so that licensing terms in some form are always available on the site. Other publisher-made specific licensing terms will be judged on an individual basis. Sometimes the publisher will choose "Other" as the answer and then wrote in the input box saying something like "We don't have a license policy at this moment, but we are going to have one in the future", this would be perceived as there is no licensing conditions exist that explicitly allow reuse and remixing of the content, thus the journal will not be accepted into DOAJ.
Publishers who restrict the re-use of content in line with any of the CC licenses are all still eligible for indexing in DOAJ. However, DOAJ has a strong preference for the use of CC licenses, especially the least restrictive: the Creative Commons CC BY license (Attribution). Under the terms of a CC BY license "you must give appropriate credit, provide a link to the license, and indicate if changes were made". "You may do so in any reasonable manner, but not in any way that suggests the licensor endorses you or your use" (from http://creativecommons.org/licenses/by/4.0/) [9].

It is also often seen in the application form that nearly all the options have been ticked probably to make the application looks more qualified. Especially for question 25 all digital archiving policies have been selected and for question 51 all deposit policy director has been selected while this is obviously not possible in practice. This might due to the lack of knowledge of these items and also would possibly make the publisher seem not serious in the application. Being straightforward with accurate information in the application form will definitely facilitate the review process of the application by reducing the unnecessary work for the reviewers to check the information given.

It should be avoided to use one URL which quite often be the URL of homepage for all the questions, as editor may think this is the start page for everything. To fill in the form, the very specific URL for the questions are expected, as this would be recorded in DOAJ and used by the public after inclusion in DOAJ. Using one URL for all question will give an impression of not being serious for the application and no need to say this will caused extra effort for the reviewer to find correct URL when review the application form.

Last but not least, the contact person of the publisher shall pay attention to the email box about the notification or communication emails sent from an editor or reviewer from DOAJ. In general, during the review process, comments and suggestion for improve would be sent to the journal contact and it is expected that there would be response to these comments or suggestion. If no answer has been received then a rejection decision would have to be made in case the journal are not qualified at this moment. So it would benefit both sides if journal contact would keep an eye on the emails and respond as fast as possible.

\section{Conclusion}

Being listed in DOAJ is the basic action as editors or publishers of open access journal. Although it is not mandatory to be listed in DOAJ, it is the best window to find the open access journals by authors and readers. Therefore, I urge all open access society journal editors and publishers especially in Asia 
to register their journals in DOAJ. I remind again that the most important point is the genuine open access journal policy adopted by the journal. I hope above explanation be helpful for registration.

\section{Conflict of Interest}

No potential conflict of interest relevant to this article was reported.

\section{References}

1. Archambault E, Amyot D, Caruso J, et al. Summary report: evolution of open access policies and availability, 1996-2013 [Internet]. Montreal: Science-Metrix; 2014 [cited 2017 Feb 1]. Available from: http://science-metrix. com/en/publications/reports/summary-report-evolutionof-open-access-policies-and-availability-1996-2013

2. Directory of Open Access Journals. About DOAJ [Internet]. Directory of Open Access Journals; 2016 [cited 2016 Dec 21]. Available from: https://doaj.org/about

3. Olijhoek T, Mitchell D, Bjornshauge L. Criteria for open access and publishing [Internet]. Burlington, MA: ScienceOpen.com; 2015 [cited 2017 Feb 1]. Available from: https://www.scienceopen.com/document?id=b34b287d1e7f-4f7c-b5b6-ecdd19bcacef

4. Scopus. Scopus to launch open access indicator for journals on July 29 [Internet]. Scopus; 2015 [cited 2016 Dec 25]. Available from: https://blog.scopus.com/posts/scopus-to-launch-open-access-indicator-for-journals-on-july-29\#.VayHUk8V7vc.twitter

5. Directory of Open Access Journals. Principles of transparency and best practice in scholarly publishing [Internet]. Directory of Open Access Journals; 2015 [cited 2016 Dec 23]. Available from: https://doaj.org/bestpractice.

6. Directory of Open Access Journals. Journal application form [Internet]. Directory of Open Access Journals; 2016 [cited 2016 Dec 21]. Available from: https://doaj.org/application/new

7. Directory of Open Access Journals. Final call! Journal reapplications to DOAJ close 31 March [Internet]. Directory of Open Access Journals; 2016 [cited 2016 Dec 21]. Available from: https://doajournals.wordpress.com/2016/03/30/ final-call-journal-reapplications-to-doaj-close-31-march/

8. Budapest Open Access Initiative. Ten years on from the
Budapest Open Access Initiative: setting the default to open [Internet]. Budapest Open Access Initiative; 2012 [cited 2016 Dec 24]. Available from: http://www.budapestopenaccessinitiative.org/boai-10-recommendations

9. Directory of Open Access Journals. Information for publishers [Internet]. Directory of Open Access Journals; 2016 [cited 2016 Dec 24]. Available from: https://doaj.org/publishers.

10. LOCKSS. Lots of copies keep stuff safe [Internet]. Stanford, CA: Stanford University [cited 201623 Dec]. Available from: https://www.lockss.org/

11. CLOCKSS. The LOCKSS archive: a trusted communitygoverned archive [Internet]. CLOCKSS; 2015 [cited 2016 Dec 23]. Available from: https://clockss.org/clockss/Home

12. PORTICO. About us [Internet]. Ann Arbor, MI: ITHAKA [cited 2016 Dec 23]. Available from: http://www.portico. org/digital-preservation/about-us

13. PubMed Central. PMC International [Internet]. Bethesda, MD: US National Library of Medicine [cited 2016 Dec 23]. Available from: https://www.ncbi.nlm.nih.gov/pmc/ about/pmci/

14. International DOI Foundation. The DOI system [Internet]. International DOI Foundation; 2016 [cited 2016 Dec 23]. Available from: https://www.doi.org/index.html

15. Handle.Net Registry. HDL.NET information service [Internet]. Reston, VA: Corporation for National Research Initiatives; 2015 [cited 2016 Dec 23]. Available from: http:// www.handle.net/

16. Willett P. ARK [Internet]. Confluence; 2016 [cited 2016 Dec 23]. Available from: https://confluence.ucop.edu/display/Curation/ARK

17. SHERRA/RoMEO. About RoMEO [Internet]. University of Nottingham; 2016 [cited 2016 Dec 23]. Available from: http://www.sherpa.ac.uk/romeo/about.php?la=en\&fIDnum= |\&mode=simple

18. Dulcinea [Internet]. Grupo de Investigacion; 2008 [cited 2016 Dec 23]. Available from: http://www.accesoabierto. net/dulcinea/

19. Heloise. Welcome to Heloise [Internet]. Campus de la Doua: CCSD [cited 2016 Dec 23]. Available from: http:// heloise.ccsd.cnrs.fr/

20. Diadorim [Internet]. Rio de Janeiro: Instituto Brasileiro de Informacao em Ciencia e Tecnologia [cited 2016 Dec 23]. Available from: http://diadorim,ivict.br/ 